\title{
UNSTEADY HYDROMAGNETIC COUETTE FLOW DUE TO RAMPED MOTION OF ONE OF THE POROUS PLATES
}

\author{
B.K. JHA and H.M. JIBRIL ${ }^{*}$ \\ Department of Mathematics, Faculty of Science \\ Ahmadu Bello University, Zaria, NIGERIA \\ E-mail: basant777@yahoo.co.uk \\ E-mail: alharun2004@yahoo.com
}

\begin{abstract}
An unsteady flow formation in Couette motion of an electrically conducting fluid subject to transverse magnetic field has been analyzed in the presence of suction/injection through the porous plates when one of the porous plates is in ramped motion. It is assumed that the porous plates are uniformly permeable and the fluid is entering the flow region through one of the porous plates at same rate as it is leaving through the other porous plate. The resulting boundary value problem has been solved exactly under the assumption of a negligible induced magnetic field, external electric field and pressure gradient. Unified closed form expressions for the velocity field and skin-friction corresponding to the case of a magnetic field fixed relative to the fluid or to the moving porous plate have been presented. In order to highlight the impact of the ramp motion of the porous plate on the fluid flow, it has also been compared with Couette flow between porous plates when one of the porous plates has been set into an impulsive motion.
\end{abstract}

Key words: Couette flow, transverse magnetic field, suction/injection, MHD, ramp motion, Hartmann number, porous plates.

\section{Introduction}

The study of the effects of a magnetic field on the laminar flow of an incompressible electrically conducting fluid in a channel is an important problem with applications to many engineering problems. These applications abide in areas such as MHD power generators, MHD pumps, aerodynamic heating, nuclear reactor cooling, etc. Such problems have engaged the attention of several researchers. Hartmann (1937) studied the influence of a transverse, uniform, magnetic field on the flow of a conducting fluid between two infinite parallel plates. Since then a lot of research work concerning the Hartmann flow has been done under different physical situations (Schlichting and Gerstein, 2000; White, 1991; Panton, 1996; Longwell, 1966; Katagiri, 1962; Singh and Kumar, 1983).

Shalybkov (2006) discussed the stability of the hydrodynamic and hydromagnetic Couette flow. A detailed study of the effects of rotation and the magnetic field on an unsteady MHD Couette flow was carried out by Chandran et al. (1993), Guria et al. (2006) and Singh et al. (1994). This work is further extended by Jha and Apere (2010), taking into account the additional effects of Hall current and ion slip. A theoretical analysis of an unsteady MHD flow through and bounded by two parallel porous plates the lower plate being stationary and the other moving in its own plane is presented by Hassanien and Mansour (1990). In all the above discussed works, flow formation is due to impulsive/ accelerated motion of the plate. Recently, Jha and Jibril (2012) investigated the effects of transpiration on the MHD Flow near a porous plate having ramped motion. He observed among others that the impact of the magnetic field is to increase the velocity when the magnetic field is fixed with respect to the moving porous plate, which is the reverse when it is fixed with respect to the fluid. The objective of the present work is to study the unsteady hydromagnetic

\footnotetext{
* To whom correspondence should be addressed
} 
Couette flow between two parallel porous plates due to ramped motion of one of the porous plates. It is assumed that both plates are uniformly permeable and that the fluid enters and leaves the porous plates at the same constant rate.

\section{Governing equations and solutions}

The physical configuration of the flow is shown in Fig. 1 in which we considered the motion of a viscous, incompressible and electrically conducting fluid between two infinite parallel porous plates due to the ramped motion of the lower plate.

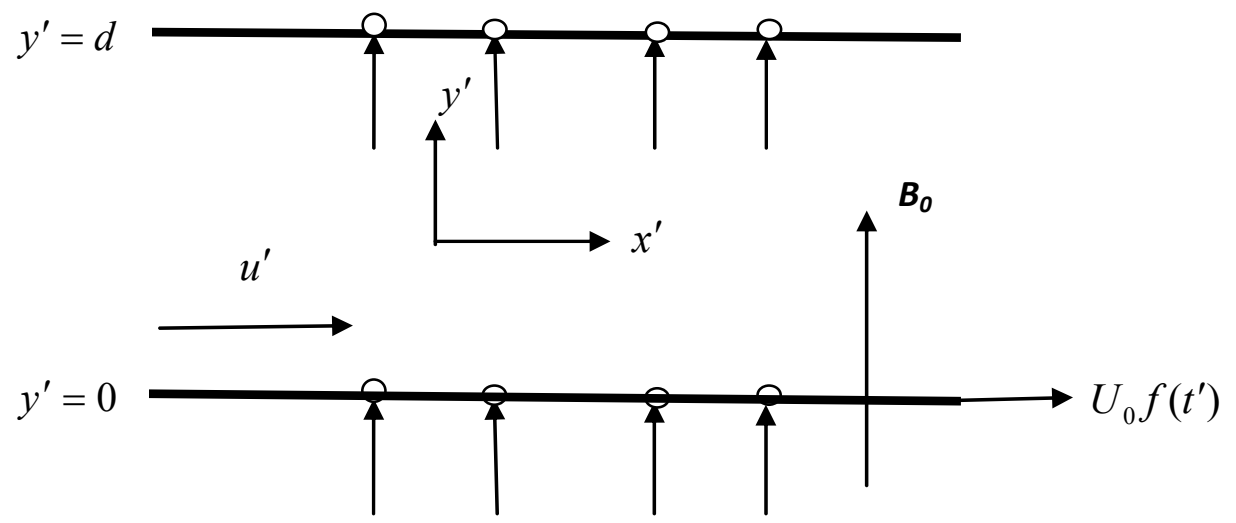

Fig.1. Flow configuration.

The $x^{\prime}$-axis is chosen along the lower plate in the horizontal direction and the $y^{\prime}$-axis normal to it. The fluid flows between the two porous plates in the $x^{\prime}$-direction in the presence of a uniform magnetic field acting normal to the flow direction. At time $t^{\prime} \leq 0$, the fluid, the porous plates and the magnetic lines of force are assumed to be at rest. At time $t^{\prime}>0$ the porous plates begins to move in its own plane with a velocity proportional to $U_{0} f\left(t^{\prime}\right)$. A uniform magnetic field of strength $B_{0}$ is acting perpendicular to the porous plates. The magnetic Reynolds number of the flow is assumed to be small enough so that the induced magnetic field can be neglected. The flow is assumed to be in the $x^{\prime}$ direction along the porous plate and the $y^{\prime}$ axis is normal to the porous plate. Since the porous plates are infinite in extent all physical variables are functions of a $y^{\prime}$ and $t^{\prime}$ only.

The momentum equation for this investigation based on the above physical conditions is

$$
\frac{\partial u^{\prime}}{\partial t^{\prime}}+V_{0} \frac{\partial u^{\prime}}{\partial y^{\prime}}=v \frac{\partial^{2} u^{\prime}}{\partial y^{\prime 2}}-\frac{\sigma B_{0}^{2}}{\rho} u^{\prime}
$$

Equation (2.1) is valid when the magnetic lines of force are fixed relative to the fluid. If the magnetic field is also in ramp motion with the same velocity as the porous plate the relative motion must be accounted for. In this case Eq.(2.1) is replaced by Chandran et al. (1993)

$$
\frac{\partial u^{\prime}}{\partial t^{\prime}}+V_{0} \frac{\partial u^{\prime}}{\partial y^{\prime}}=v \frac{\partial^{2} u^{\prime}}{\partial y^{\prime 2}}-\frac{\sigma B_{0}^{2}}{\rho}\left[u^{\prime}-U_{0} f\left(t^{\prime}\right)\right]
$$


which is valid when the magnetic lines of force are fixed relative to the moving porous plate.

Equations (2.1) and (2.2) can be combined together to obtain

$$
\frac{\partial u^{\prime}}{\partial t^{\prime}}+V_{0} \frac{\partial u^{\prime}}{\partial y^{\prime}}=v \frac{\partial^{2} u^{\prime}}{\partial y^{\prime 2}}-\frac{\sigma B_{0}^{2}}{\rho}\left[u^{\prime}-K U_{0} f\left(t^{\prime}\right)\right]
$$

where

$$
K=\left\{\begin{array}{l}
0 \text { if the magnetic field is fixed relative to the fluid } \\
1 \text { if the magnetic field is fixed relative to the plate }
\end{array}\right.
$$

The initial and boundary conditions are

$$
\begin{aligned}
& t^{\prime} \leq 0: u^{\prime}=0, \quad \text { for } \quad 0 \leq y^{\prime} \leq d, \\
& t^{\prime}>0:\left\{\begin{array}{l}
u^{\prime}=U_{0} f\left(t^{\prime}\right) \quad \text { at } \quad y^{\prime}=0, \\
u^{\prime}=0 \quad \text { at } \quad y^{\prime}=d .
\end{array}\right.
\end{aligned}
$$

Introducing the non-dimensionless quantities

$$
y=\frac{y^{\prime} U_{0}}{v}, \quad t=\frac{t^{\prime} U_{0}^{2}}{v}, \quad u=\frac{u^{\prime}}{U_{0}}, \quad \mathrm{M}^{2}=\frac{\sigma B_{0}^{2} v}{\rho U_{0}^{2}}, \quad h=\frac{d U_{0}}{v}, \quad S=\frac{V_{0}}{U_{0}}
$$

where all the physical quantities are defined in the nomenclature, the momentum Eq.(2.3) becomes

$$
\frac{\partial u}{\partial t}+S \frac{\partial u}{\partial y}=\frac{\partial^{2} u}{\partial y^{2}}-\mathrm{M}^{2}[u-K f(t)]
$$

The initial and boundary conditions Eq.(2.4) in the dimensionless form for the physical system considered in the present study are

For

$$
\begin{aligned}
& t \leq 0, \quad u=0 \quad \text { for all } \quad y \geq 0, \\
& t>0,\left\{\begin{array}{lll}
u=f(t) & \text { at } & y=0, \\
u=0 & \text { at } & y=h .
\end{array}\right.
\end{aligned}
$$

In the present work $f(t)$ is specified as the ramp function

$$
\begin{array}{rlrl}
f(t) & =\frac{t}{t_{0}} \quad \text { if } & & 0 \leq t \leq t_{0}, \\
& =1 \quad \text { if } & t>t_{0} .
\end{array}
$$


Equation (2.7) can be written as

$$
f(t)=H(t)\left(\frac{t}{t_{0}}\right)-\left(\frac{1 .}{t_{0}}\right)\left(t-t_{0}\right) H\left(t-t_{0}\right) .
$$

The solution of the partial differential Eq.(2.5) subject to conditions (2.6) is attempted by the operational method of Laplace transformation, (Carslaw and Jaeger, 1963). Let

$$
L[u(y, t)]=\bar{u}(y, s)=\int_{0}^{\infty} u(y, t) \exp (-s t) d t
$$

be the Laplace transform of $u(y, t)$, then Eqs (2.5), (2.6) and (2.7) reduce to

$$
\begin{aligned}
& \frac{d^{2} \bar{u}}{d y^{2}}-S \frac{d \bar{u}}{d y}-\left(\mathrm{M}^{2}+s\right) \bar{u}=-K \mathrm{M}^{2} \bar{f}(s), \\
& t \leq 0, \quad \bar{u}=0 \quad \text { for all } \quad y \geq 0, \\
& t>0, \quad\left\{\begin{array}{lll}
\bar{u}=f(s) & \text { at } & y=0, \\
\bar{u}=0 & \text { at } & y=h,
\end{array}\right. \\
& \bar{f}(s)=\frac{\left[1 .-\operatorname{Exp}\left(-s t_{0}\right)\right]}{s^{2} t_{0}} .
\end{aligned}
$$

The solution of Eq.(2.10), under the conditions (2.11) and (2.12), is

$$
\begin{aligned}
& \bar{u}=\frac{\operatorname{Exp}\left(\frac{S y}{2}\right)}{t_{0} s^{2}}\left[1 .-\operatorname{Exp}\left(-s t_{0}\right)\right] \sum_{m=0}^{\infty}\left[\left(1 .-\frac{K \mathrm{M}^{2}}{\left(\mathrm{M}^{2}+s\right)}\right)\left(\begin{array}{c}
\operatorname{Exp}\left(-a_{1} \sqrt{C^{2}+s}\right)+ \\
-\operatorname{Exp}\left(-a_{2} \sqrt{C^{2}+s}\right)
\end{array}\right)+\right. \\
& \left.+\left(\frac{K \mathrm{M}^{2}}{\left(\mathrm{M}^{2}+s\right)}\right) \operatorname{Exp}\left(\frac{\mathrm{Sh}}{2}\right)\left(\operatorname{Exp}\left(-a_{3} \sqrt{C^{2}+s}\right)-\operatorname{Exp}\left(-a_{4} \sqrt{C^{2}+s}\right)\right)\right]+ \\
& +\frac{K \mathrm{M}^{2}}{\left(\mathrm{M}^{2}+s\right) t_{0} s^{2}}\left[1 .-\operatorname{Exp}\left(-s t_{0}\right)\right]
\end{aligned}
$$

where 


$$
\begin{array}{ll}
a_{1}=2 m h+y, & a_{2}=2 m h+2 h-y, \quad a_{3}=2 m h+h+y, \\
a_{4}=2 m h+h-y, & C^{2}=\left(\frac{S^{2}}{4}+\mathrm{M}^{2}\right) .
\end{array}
$$

In Eq.(2.13), the summation term is due to expansion of the term $\left[1 .-\operatorname{Exp}\left(-2 h \sqrt{C^{2}+s}\right)\right]^{-1}$ by Binomial theorem.

The exact solution for velocity field can be obtained from Eq.(2.13), by taking the inverse transforms (Abramowitz and Stegun, 1965; Carslaw and Jaeger, 1963). After detailed simplifications and shifting on the $t$-axis, the solution can be expressed as

$$
\begin{aligned}
& u(y, t)=\frac{\operatorname{Exp}\left(\frac{S y}{2}\right)}{t_{0}} \sum_{m=0}^{\infty}\left[F_{1}\left(a_{1} ; C ; t ; 0.0\right)-F_{1}\left(a_{2} ; C ; t: 0.0\right)+\right. \\
& -H\left(t-t_{0}\right)\left(F_{1}\left(a_{1} ; C ; t ; t_{0}\right)-F_{1}\left(a_{2} ; C ; t: t_{0}\right)\right)+ \\
& -K\left(F_{1}\left(a_{1} ; C ; t ; 0.0\right)-F_{1}\left(a_{2} ; C ; t ; 0.0\right)+\right. \\
& \left.-\operatorname{Exp}\left(-\frac{\mathrm{Sh}}{2}\right)\left(F_{1}\left(a_{3} ; C ; t ; 0.0\right)-F_{1}\left(a_{4} ; C ; t ; 0.0\right)\right)\right)+ \\
& +K H\left(t-t_{0}\right)\left(F_{l}\left(a_{1} ; C ; t ; t_{0}\right)-F_{l}\left(a_{2} ; C ; t ; t_{0}\right)+\right. \\
& \left.-\operatorname{Exp}\left(-\frac{\mathrm{Sh}}{2}\right)\left(F_{l}\left(a_{3} ; C ; t ; t_{0}\right)-F_{l}\left(a_{4} ; C ; t ; t_{0}\right)\right)\right)+ \\
& +\frac{K}{\mathrm{M}^{2}}\left(F_{2}\left(a_{1} ; C ; t ; 0.0\right)-F_{2}\left(a_{2} ; C ; t ; 0.0\right)+\right. \\
& \left.-\operatorname{Exp}\left(-\frac{\mathrm{Sh}}{2}\right)\left(F_{2}\left(a_{3} ; C ; t ; 0.0\right)-F_{2}\left(a_{4} ; C ; t ; 0.0\right)\right)\right)+ \\
& -\frac{K}{\mathrm{M}^{2}} H\left(t-t_{0}\right)\left(F_{2}\left(a_{1} ; C ; t ; t_{0}\right)-F_{2}\left(a_{2} ; C ; t ; t_{0}\right)+\right. \\
& -\operatorname{Exp}\left(-\frac{\mathrm{Sh}}{2}\right)\left(F_{2}\left(a_{3} ; C ; t ; t_{0}\right)-F_{2}\left(a_{4} ; C ; t ; t_{0}\right)\right)+ \\
& +\frac{K}{\mathrm{M}^{2}} \operatorname{Exp}\left(-\mathrm{M}^{2} t\right)\left(\begin{array}{l}
F_{2}\left(a_{1} ; \frac{S}{2} ; t ; 0.0\right)-F_{2}\left(a_{2} ; \frac{S}{2} ; t ; 0.0\right)+ \\
-\operatorname{Exp}\left(-\frac{\mathrm{Sh}}{2}\right)\left(F_{2}\left(a_{3} ; \frac{S}{2} ; t ; 0.0\right)-F_{2}\left(a_{4} ; \frac{S}{2} ; t ; 0.0\right)\right)
\end{array}\right)+
\end{aligned}
$$

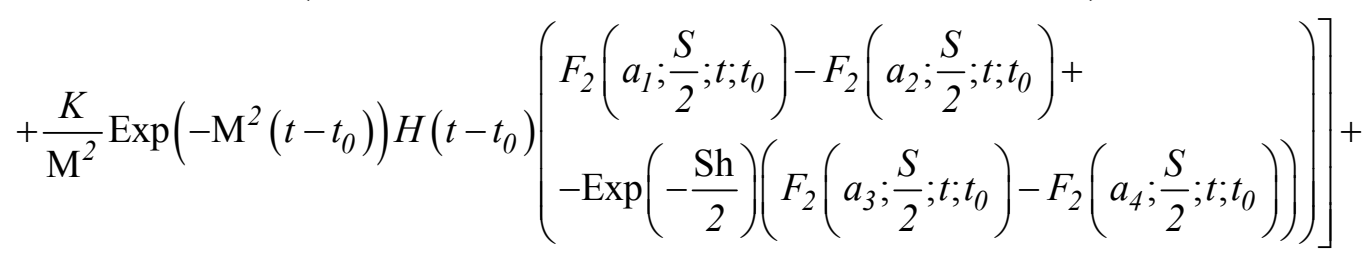




$$
-\frac{K}{t_{0}}\left[\frac{1}{\mathrm{M}^{2}}-\frac{\operatorname{Exp}\left(-\mathrm{M}^{2} t\right)}{\mathrm{M}^{2}}-t\right]+\frac{K}{t_{0}} H\left(t-t_{0}\right)\left[\frac{1}{\mathrm{M}^{2}}-\frac{\operatorname{Exp}\left(-\mathrm{M}^{2}\left(t-t_{0}\right)\right)}{\mathrm{M}^{2}}-\left(t-t_{0}\right)\right]
$$

Using the expression (2.14), the frictional forces acting at the lower and upper plates are

$$
\begin{aligned}
& \tau_{0}=\left.\frac{\partial u}{\partial y}\right|_{y=0}= \\
& =\frac{1}{t_{0}} \sum_{m=0}^{\infty}\left[\frac{S}{2} F_{1}\left(b_{1} ; C ; t ; 0.0\right)+F_{3}\left(b_{1} ; C ; t: 0.0\right)-\left(\frac{S}{2} F_{1}\left(b_{2} ; C ; t ; 0.0\right)-F_{3}\left(b_{2} ; C ; t: 0.0\right)\right)+\right. \\
& -H\left(t-t_{0}\right)\left(\frac{S}{2} F_{1}\left(b_{1} ; C ; t ; 0.0\right)+F_{3}\left(b_{1} ; C ; t: 0.0\right)-\left(\frac{S}{2} F_{l}\left(b_{2} ; C ; t ; t_{0}\right)-F_{3}\left(b_{2} ; C ; t: t_{0}\right)\right)\right)+ \\
& -K\left(\frac{S}{2} F_{l}\left(b_{1} ; C ; t ; 0.0\right)+F_{3}\left(b_{1} ; C ; t: 0.0\right)-\left(\frac{S}{2} F_{l}\left(b_{2} ; C ; t ; 0.0\right)-F_{3}\left(b_{2} ; C ; t: 0.0\right)\right)+\right. \\
& \left.-2 \operatorname{Exp}\left(-\frac{\mathrm{Sh}}{2}\right) F_{3}\left(b_{3} ; C ; t: 0.0\right)\right)+ \\
& +K H\left(t-t_{0}\right)\left(\frac{S}{2} F_{1}\left(b_{1} ; C ; t ; t_{0}\right)+F_{3}\left(b_{1} ; C ; t: t_{0}\right)-\left(\frac{S}{2} F_{1}\left(b_{2} ; C ; t ; t_{0}\right)-F_{3}\left(b_{2} ; C ; t: t_{0}\right)\right)+\right. \\
& \left.-2 \operatorname{Exp}\left(-\frac{\mathrm{Sh}}{2}\right) F_{3}\left(b_{3} ; C ; t: t_{0}\right)\right)+ \\
& +\frac{K}{\mathrm{M}^{2}}\left(\frac{S}{2} F_{2}\left(b_{1} ; C ; t ; 0.0\right)+F_{4}\left(b_{1} ; C ; t: 0.0\right)-\left(\frac{S}{2} F_{2}\left(b_{2} ; C ; t ; 0.0\right)-F_{4}\left(b_{2} ; C ; t: 0.0\right)\right)+\right. \\
& \left.-2 \operatorname{Exp}\left(-\frac{\mathrm{Sh}}{2}\right) F_{4}\left(b_{3} ; C ; t: 0.0\right)\right)+ \\
& -\frac{K}{\mathrm{M}^{2}} H\left(t-t_{0}\right)\left(\frac{S}{2} F_{2}\left(b_{1} ; C ; t ; t_{0}\right)+F_{4}\left(b_{1} ; C ; t: t_{0}\right)-\left(\frac{S}{2} F_{2}\left(b_{2} ; C ; t ; t_{0}\right)-F_{4}\left(b_{2} ; C ; t: t_{0}\right)\right)+\right. \\
& \left.-2 \operatorname{Exp}\left(-\frac{\mathrm{Sh}}{2}\right) F_{4}\left(b_{3} ; C ; t: t_{0}\right)\right)+ \\
& -\frac{K \operatorname{Exp}\left(-\mathrm{M}^{2} t\right)}{\mathrm{M}^{2}}\left(\frac{S}{2} F_{2}\left(b_{1} ; \frac{S}{2} ; t ; 0.0\right)+F_{4}\left(b_{1} ; \frac{S}{2} ; t: 0.0\right)-\left(\frac{S}{2} F_{2}\left(b_{2} ; \frac{S}{2} ; t ; 0.0\right)\right)+\right. \\
& \left.-F_{4}\left(b_{2} ; \frac{S}{2} ; t: 0.0\right)-2 \operatorname{Exp}\left(-\frac{\mathrm{Sh}}{2}\right) F_{4}\left(b_{3} ; \frac{S}{2} ; t: 0.0\right)\right)+ \\
& +\frac{K \operatorname{Exp}\left(-\mathrm{M}^{2}\left(t-t_{0}\right)\right)}{\mathrm{M}^{2}} H\left(t-t_{0}\right)\left(\frac{S}{2} F_{2}\left(b_{1} ; \frac{S}{2} ; t ; t_{0}\right)+\right. \\
& \left.\left.+F_{4}\left(b_{1} ; \frac{S}{2} ; t: t_{0}\right)-\left(\frac{S}{2} F_{2}\left(b_{2} ; \frac{S}{2} ; t ; t_{0}\right)-F_{4}\left(b_{2} ; \frac{S}{2} ; t: t_{0}\right)\right)-2 \operatorname{Exp}\left(-\frac{\mathrm{Sh}}{2}\right) F_{4}\left(b_{3} ; \frac{S}{2} ; t: t_{0}\right)\right)\right],
\end{aligned}
$$




$$
\begin{aligned}
& \tau_{h}=\left.\frac{\partial u}{\partial y}\right|_{y=h}= \\
& =\frac{1}{t_{0}} \sum_{m=0}^{\infty}\left[2\left(F_{3}\left(c_{1} ; C ; t: 0.0\right)-H\left(t-t_{0}\right) F_{3}\left(c_{1} ; C ; t: 0.0\right)\right)+\right. \\
& -K\left(\begin{array}{l}
2 F_{3}\left(c_{1} ; C ; t: 0.0\right)-\operatorname{Exp}\left(-\frac{\mathrm{Sh}}{2}\right)\left\{\frac{S}{2} F_{1}\left(c_{3} ; C ; t ; 0.0\right)+\right. \\
\left.+F_{3}\left(c_{3} ; C ; t: 0.0\right)-\left(\frac{S}{2} F_{1}\left(c_{4} ; C ; t ; 0.0\right)-F_{3}\left(c_{4} ; C ; t: 0.0\right)\right)\right\}
\end{array}\right)+ \\
& +K H\left(t-t_{0}\right)\left(\begin{array}{l}
2 F_{3}\left(c_{1} ; C ; t: t_{0}\right)-\operatorname{Exp}\left(-\frac{\mathrm{Sh}}{2}\right)\left\{\frac{S}{2} F_{1}\left(c_{3} ; C ; t ; t_{0}\right)+\right. \\
\left.+F_{3}\left(c_{3} ; C ; t: t_{0}\right)-\left(\frac{S}{2} F_{1}\left(c_{4} ; C ; t ; t_{0}\right)-F_{3}\left(c_{4} ; C ; t: t_{0}\right)\right)\right\}
\end{array}\right)+ \\
& +\frac{K}{\mathrm{M}^{2}}\left(\begin{array}{l}
2 F_{4}\left(c_{1} ; C ; t: 0.0\right)-\operatorname{Exp}\left(-\frac{\mathrm{Sh}}{2}\right)\left\{\frac{S}{2} F_{2}\left(c_{3} ; C ; t ; 0.0\right)+\right. \\
\left.+F_{4}\left(c_{3} ; C ; t: 0.0\right)-\left(\frac{S}{2} F_{2}\left(c_{4} ; C ; t ; 0.0\right)-F_{4}\left(c_{4} ; C ; t: 0.0\right)\right)\right\}
\end{array}\right)+ \\
& -\frac{K}{\mathrm{M}^{2}} H\left(t-t_{0}\right)\left(\begin{array}{l}
2 F_{4}\left(c_{1} ; C ; t: t_{0}\right)-\operatorname{Exp}\left(-\frac{\mathrm{Sh}}{2}\right)\left\{\frac{S}{2} F_{2}\left(c_{3} ; C ; t ; t_{0}\right)+\right. \\
\left.+F_{4}\left(c_{3} ; C ; t: t_{0}\right)-\left(\frac{S}{2} F_{2}\left(c_{4} ; C ; t ; t_{0}\right)-F_{4}\left(c_{4} ; C ; t: t_{0}\right)\right)\right\}
\end{array}\right)+
\end{aligned}
$$

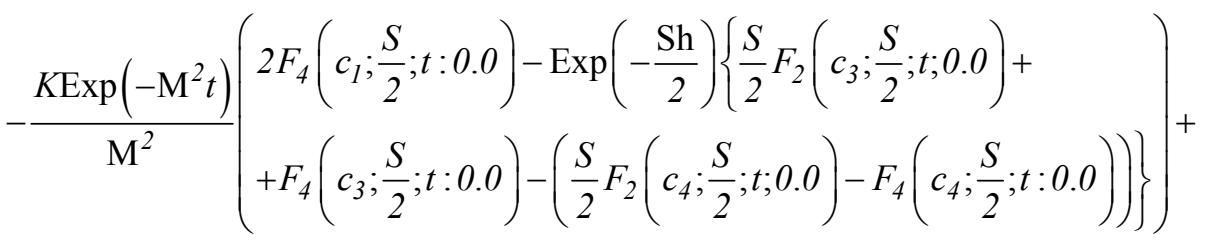

$$
\begin{aligned}
& \left.+\frac{K \operatorname{Exp}\left(-\mathrm{M}^{2}\left(t-t_{0}\right)\right)}{\mathrm{M}^{2}} H\left(t-t_{0}\right)\left(\begin{array}{l}
2 F_{4}\left(c_{1} ; \frac{S}{2} ; t ; t_{0}\right)-\operatorname{Exp}\left(-\frac{\mathrm{Sh}}{2}\right)\left\{\frac{S}{2} F_{2}\left(c_{3} ; \frac{S}{2} ; t ; t_{0}\right)+\right. \\
+F_{4}\left(c_{3} ; \frac{S}{2} ; t: t_{0}\right)-\left(\frac{S}{2} F_{2}\left(c_{4} ; \frac{S}{2} ; t ; t_{0}\right)-F_{4}\left(c_{4} ; \frac{S}{2} ; t: t_{0}\right)\right)
\end{array}\right)\right\}
\end{aligned}
$$

where

$$
\begin{array}{lrl}
b_{1}=2 m h, & b_{2}=2 m h+2 h, & b_{3}=2 m h+h, \\
c_{1}=2 m h+h, & c_{3}=2 m h+2 h, & c_{4}=2 m h .
\end{array}
$$

Special case: Impulsive motion of one of the porous plates

For $t_{0}=0$, the expression (2.14) reduces to 


$$
\begin{aligned}
& u(y, t)=\operatorname{Exp}\left(\frac{S y}{2}\right) \sum_{m=0}^{\infty}\left[\left[(1 .-K)\left[F_{2}\left(a_{1} ; C ; t ; 0.0\right)-F_{2}\left(a_{2} ; C ; t ; 0 ; 0\right)\right]+\right.\right. \\
& +K \operatorname{Exp}\left(-\mathrm{M}^{2} t\right)\left[F_{2}\left(a_{1} ; \frac{S}{2} ; t ; 0.0\right)-F_{2}\left(a_{2} ; \frac{S}{2} ; t ; 0.0\right)\right]+ \\
& +K \operatorname{Exp}\left(-\frac{\mathrm{Sh}}{2}\right)\left[F_{2}\left(a_{3} ; c ; t ; 0.0\right)-F_{2}\left(a_{4} ; c ; t ; 0.0\right)\right]+ \\
& +K \operatorname{Exp}\left(-\frac{\mathrm{Sh}}{2}\right) \operatorname{Exp}\left(-\mathrm{M}^{2} t\right)\left[F_{2}\left(a_{3} ; \frac{S}{2} ; t ; 0.0\right)-F_{2}\left(a_{4} ; \frac{S}{2} ; t ; 0.0\right)\right]+ \\
& +\left[K \operatorname{Exp}\left(-\mathrm{M}^{2} t\right)\right]
\end{aligned}
$$

and the skin friction at the lower and upper plates is, respectively

$$
\begin{aligned}
& \tau_{0}=-\left.\frac{\partial u}{\partial y}\right|_{y=0}= \\
& =\sum_{m=0}^{\infty}\left[\frac { S } { 2 } \left[(1 .-K)\left[F_{2}\left(b_{1_{1}} ; C ; t ; 0.0\right)-F_{2}\left(b_{2} ; C ; t ; 0 ; 0\right)\right]+\right.\right. \\
& \left.+K \operatorname{Exp}\left(-\mathrm{M}^{2} t\right)\left[F_{2}\left(b_{1} ; \frac{S}{2} ; t ; 0.0\right)-F_{2}\left(b_{2} ; \frac{S}{2} ; t ; 0.0\right)\right]\right]+ \\
& +\left[(1 .-K)\left[F_{4_{2}}\left(b_{1} ; C ; t ; 0.0\right)+F_{4}\left(b_{2} ; C ; t ; 0 ; 0\right)\right]+\right. \\
& +K \operatorname{Exp}\left(-\mathrm{M}^{2} t\right)\left[F_{4}\left(b_{1} ; \frac{S}{2} ; t ; 0.0\right)+F_{4}\left(b_{2} ; \frac{S}{2} ; t ; 0.0\right)\right]+ \\
& \left.+2 K \operatorname{Exp}\left(-\frac{\mathrm{Sh}}{2}\right)\left[F_{4}\left(b_{3} ; c ; t ; 0.0\right)\right]-2 K \operatorname{Exp}\left(-\frac{\mathrm{Sh}}{2}\right) \operatorname{Exp}\left(-\mathrm{M}^{2} t\right)\left[F_{4}\left(b_{3_{1}} ; \frac{S}{2} ; t ; 0.0\right)\right]\right] \text {, } \\
& \tau_{h}=-\left.\frac{\partial u}{\partial y}\right|_{y=h}= \\
& =\sum_{m=0}^{\infty}\left[\frac { S } { 2 } \operatorname { E x p } \left(\frac { \mathrm { Sh } } { 2 } \left[\left(K \operatorname{Exp}\left(\frac{-\mathrm{Sh}}{2}\right)\right)\left[F_{2}\left(C_{3} ; C ; t ; 0.0\right)-F_{2}\left(C_{4} ; C ; t ; 0 ; 0\right)\right]+\right.\right.\right. \\
& \left.-K \operatorname{Exp}\left(-\mathrm{M}^{2} t\right)\left[F_{2}\left(C_{3} ; \frac{S}{2} ; t ; 0.0\right)-F_{2}\left(C_{4} ; \frac{S}{2} ; t ; 0.0\right)\right]\right]+ \\
& +2(1-K) \operatorname{Exp}\left(\frac{\mathrm{Sh}}{2}\right)\left[F_{4}\left(c_{1} ; c ; t ; 0.0\right)\right]+ \\
& +2 K \operatorname{Exp}\left(-\mathrm{M}^{2} t\right)\left[F_{4}\left(C_{1} ; \frac{S}{2} ; t ; 0.0\right)\right]+K\left[F_{4}\left(c_{3} ; c ; t ; 0.0\right)+F_{4}\left(c_{4} ; c ; t ; 0.0\right)\right]+ \\
& \left.-K \operatorname{Exp}\left(-\mathrm{M}^{2} t\right)\left[F_{4}\left(c_{3} ; \frac{S}{2} ; ; ; 0.0\right)+F_{4}\left(C_{4} ; \frac{S}{2} ; ; ; 0.0\right)\right]\right] \text {. }
\end{aligned}
$$

The functional $F_{1}, F_{2}, F_{3}$ and $F_{4}$ used in the above equations are defined as 


$$
\begin{aligned}
& F_{1}\left(X_{1} ; X_{2} ; X_{3} ; X_{4}\right)= \\
& =\frac{1 .}{2} .\left[\operatorname{Exp}\left(X_{1} \cdot X_{2}\right) \operatorname{Erfc}\left(\frac{X_{1}}{2 \sqrt{X_{3}-X_{4}}}+X_{2} \sqrt{X_{3}-X_{4}}\right)\left[\left(X_{3}-X_{4}\right)+\frac{X_{1}}{2 \cdot X_{2}}\right]+\right. \\
& \left.+\operatorname{Exp}\left(-X_{1} \cdot X_{2}\right) \operatorname{Erfc}\left(\frac{X_{1}}{2 \sqrt{X_{3}-X_{4}}}-X_{2} \sqrt{X_{3}-X_{4}}\right)\left[\left(X_{3}-X_{4}\right)-\frac{X_{1}}{2 \cdot X_{2}}\right]\right] \\
& F_{2}\left(X_{1} ; X_{2} ; X_{3} ; X_{4}\right)=\frac{1 \cdot}{2 \cdot}\left[\operatorname{Exp}\left(X_{1} \cdot X_{2}\right) \operatorname{Erfc}\left(\frac{X_{1}}{2 \sqrt{X_{3}-X_{4}}}+X_{2} \sqrt{X_{3}-X_{4}}\right)+\right. \\
& \left.+\operatorname{Exp}\left(-X_{1} \cdot X_{2}\right) \operatorname{Erfc}\left(\frac{X_{1}}{2 \sqrt{X_{3}-X_{4}}}-X_{2} \sqrt{X_{3}-X_{4}}\right)\right], \\
& F_{3}\left(X_{1} ; X_{2} ; X_{3}\right)=\left[X_{1}-X_{1} \operatorname{Erfc}\left(X_{1} \sqrt{X_{2}-X_{3}}\right)+\frac{\operatorname{Exp}\left(-X_{1}^{2}\left(X_{2}-X_{3}\right)\right)}{\left.\sqrt{\pi\left(X_{2}-X_{3}\right)}\right]}\right] \\
& F_{4}\left(X_{1} ; X_{2} ; X_{3}\right)=\left[X_{1}\left(X_{2}-X_{3}\right)+\left(\frac{1}{2 X_{1}}\right)+\sqrt{\frac{\left(X_{2}-X_{3}\right)}{\pi}} \operatorname{Exp}\left(-X_{1}^{2}\left(X_{2}-X_{3}\right)\right)+\right. \\
& \left.-\left(X_{1}\left(X_{2}-X_{3}\right)+\left(\frac{1}{2 X_{1}}\right)\right)+\sqrt{\frac{\left(X_{2}-X_{3}\right)}{\pi}} \operatorname{Exp}\left(-X_{1}^{2}\left(X_{2}-X_{3}\right)\right)\right]
\end{aligned}
$$

where Erfc is the complementary error function defined as

$$
\operatorname{Erfc}(\eta)=\frac{2}{\sqrt{\pi}} \int_{\eta}^{\infty} \operatorname{Exp}\left(-X^{2}\right) d X
$$

\section{Steady state solution}

As time increases, the response of the velocity with respect to time becomes insignificant. This implies that the flow velocity has attained its steady state value at that time. In this case the expression for velocity distribution of the problem at this state can be obtained by setting $\frac{\partial u}{\partial t}=0$ in Eq.(2.5). This reduces the equation to

$$
\frac{d^{2} u}{d y^{2}}-S \frac{d u}{d y}-\mathrm{M}^{2} u=-K \mathrm{M}^{2}
$$


Equation (3.1) is solved under the boundary conditions

$$
\begin{aligned}
& u=1 \quad \text { at } \quad y=0, \\
& u=0 \quad \text { at } \quad y=h .
\end{aligned}
$$

The solution of Eq.(3.1) subject to the boundary conditions (3.2) is expressed as

$$
u=\frac{\exp \left(\frac{S y}{2}\right)(1-K) \sinh (C(h-y))}{\sinh (C h)}+K\left[1-\frac{\exp \left(-\frac{S h}{2}\right) \exp \left(\frac{S y}{2}\right) \sinh (C y)}{\sinh (C h)}\right]
$$

where

$$
C=\sqrt{\frac{\lambda^{2}}{4}+\mathrm{M}^{2}} .
$$

Using expression (3.3), the frictional forces at the lower and upper porous plates are

$$
\begin{aligned}
& \tau_{0}=\left.\frac{d u}{d y}\right|_{y=0}=\frac{(1-K)}{\sinh (C h)}\left[\frac{S}{2} \sinh (C h)-C \cosh (C H)\right]-\frac{K C \exp \left(-\frac{S h}{2}\right)}{\sinh (C h)}, \\
& \tau_{h}=\left.\frac{d u}{d y}\right|_{y=h}=\frac{C}{\sinh (C h)}\left[(K-1) \exp \left(\frac{\operatorname{Sh}}{2}\right)-K \cosh (C h)\right]-\frac{S}{2} K .
\end{aligned}
$$

\section{Results and discussions}

In order to illustrate the effects of the controlling parameters, such as the Hartmann number, the suction/injection parameter, the velocity and skin friction where computed taking the value of $t_{0}=2$ and $h=1.0$. The results are illustrated in Figs 2 to 11 .

Figure 2 shows the variation of the velocity due to the ramp motion of the moving porous plate for different values of the suction/injection parameter $S$ when the magnetic lines of force are fixed relative to the moving porous plate or fluid for a fixed value of the magnetic field $\mathrm{M}$. It is seen from this figure that the velocity increases in the presence of the injection parameter and decreases with suction at the porous moving plate, whether the magnetic lines of force are fixed with respect to the fluid or moving porous plate. It also shows that velocity is higher when the magnetic lines of force are fixed relative to the moving porous plate than when fixed relative to the fluid in the presence of suction or injection. 


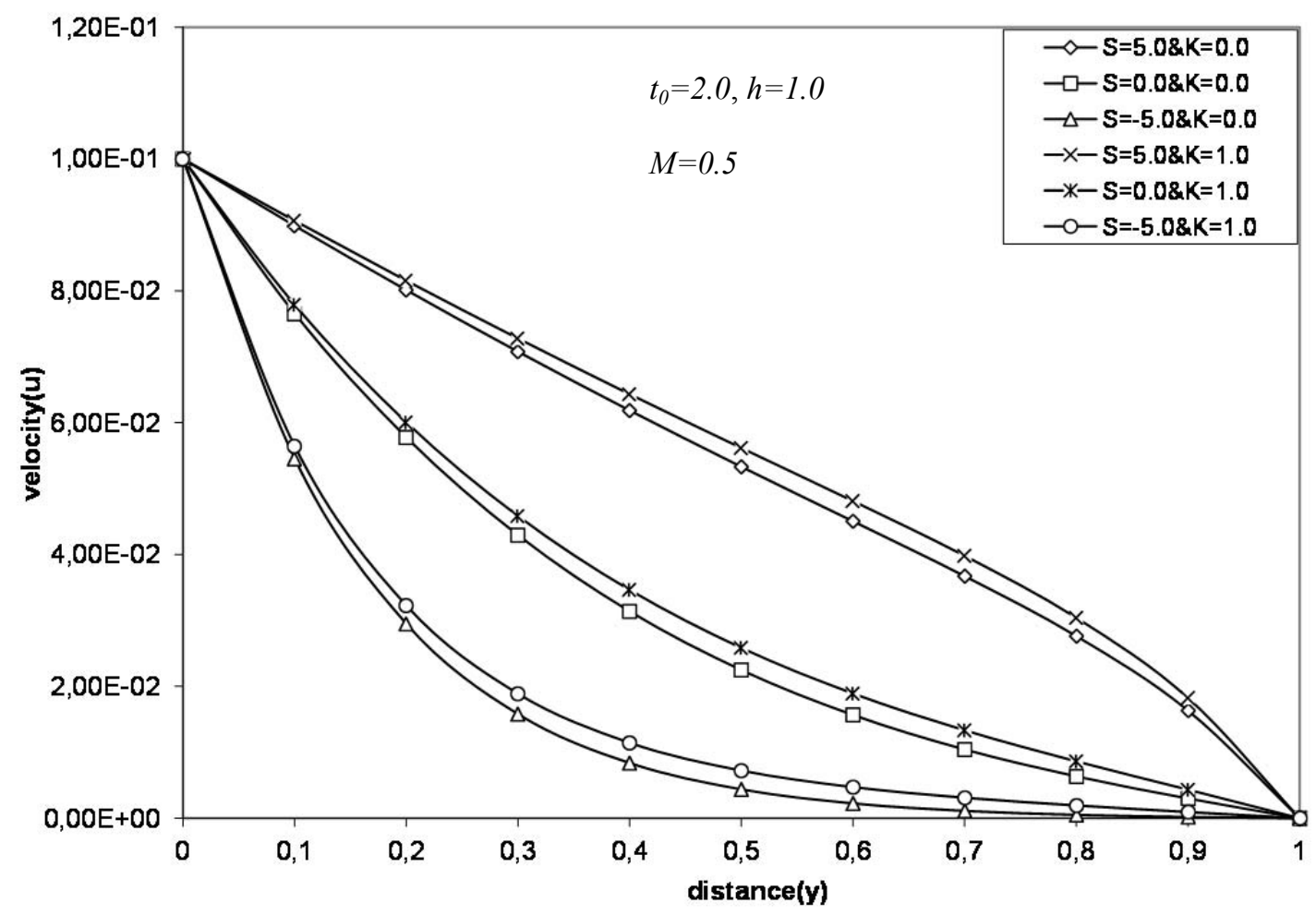

Fig.2. Variation of velocity for different values of $S$.

The variation of velocity due to the ramp motion of the porous moving plate for different values of time for a fixed magnetic field $\mathrm{M}$ with injection and suction when the magnetic lines of force are fixed relative to the fluid or moving porous plate is depicted in Figs 3 and 4, respectively.

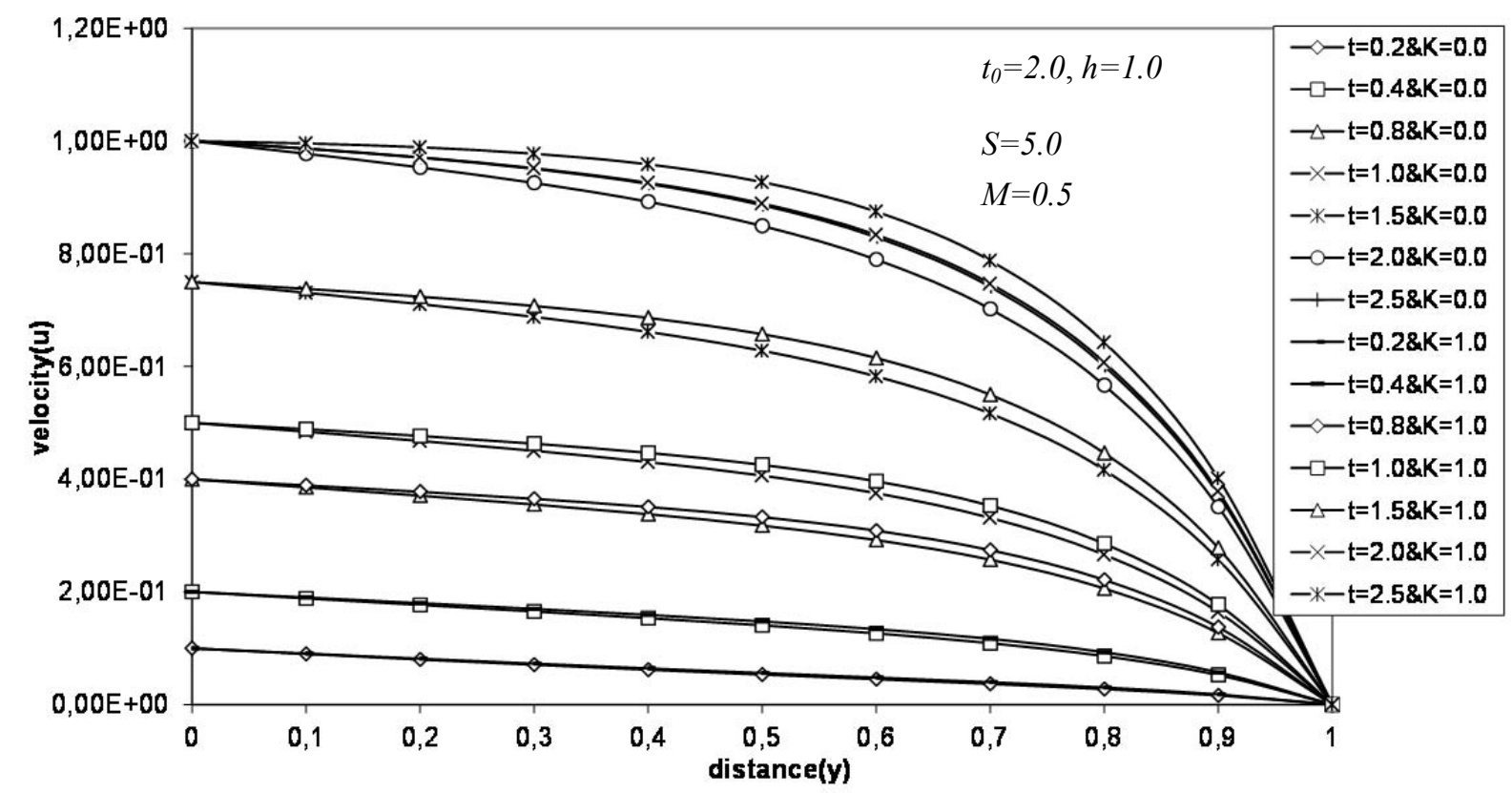

Fig.3. Variation of velocity for different values of $t$ and $K$. 


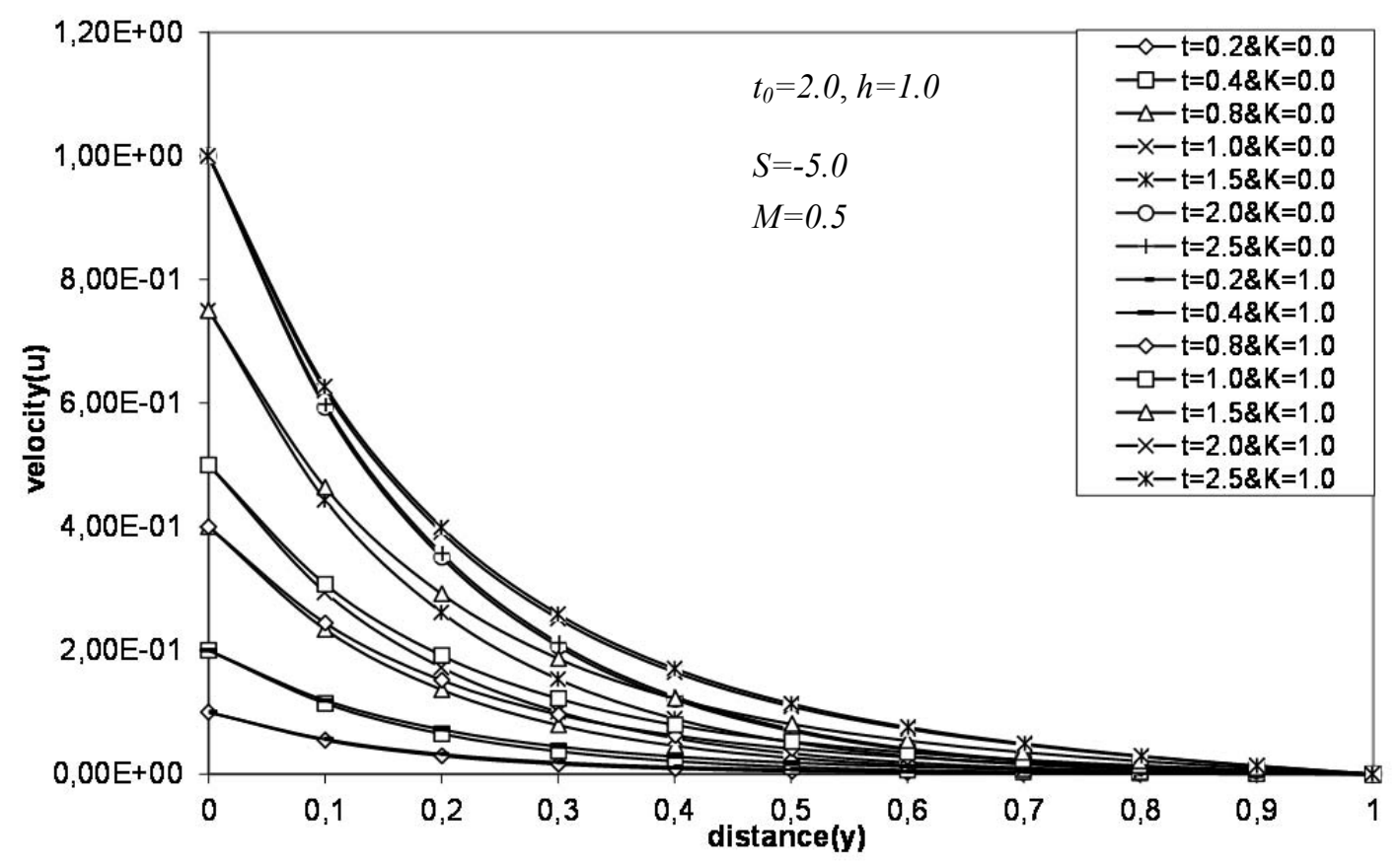

Fig.4. Variation of velocity for different time $t$ and $K$.

From these figures it is evident that velocity increases with an increase in time for a fixed value of the suction/injection parameter.

These figures also reveal that velocity is higher when the magnetic lines of force are fixed with respect to the moving porous plate than when fixed relative to the fluid.

Figure 5 presents the development of velocity due to the ramp motion of the moving porous plate for different time $t$ and $S$, when the magnetic field lines are fixed relative to the fluid or moving porous plate for a fixed value of the Hartmann number $M$. This velocity profile shows under mass suction or injection velocity increases with an increase in time, whether the magnetic lines of force are fixed relative to the fluid $(K=0)$ or moving porous plate $(K=1)$. Furthermore it is seen that velocity is higher when the magnetic lines of force are fixed relative to the moving porous plate than when fixed relative to the fluid whether there is injection or suction at the moving porous plate.

Figures 6 and 7 illustrate velocity variation due to the ramp and impulsive motion of the porous plate for different values of time, and the injection/suction parameter, for fixed $\mathrm{M}$ for $K=0.0$ and $K=1.0$, respectively. From these figures it is observed that when the magnetic lines of force are fixed relative to the fluid $(K=0.0)$ or relative to the moving porous plate $(K=1.0)$ velocity increases with an increase in time, in the presence of mass injection or suction, due to the ramp or impulsive motion of the porous plate. These figures also show that injection increases the velocity while suction reduces it. It is also evident that the velocity due to the impulsive motion is higher than the velocity due to the ramp motion when the magnetic lines of force are fixed with respect to the moving porous plate of fluid. 


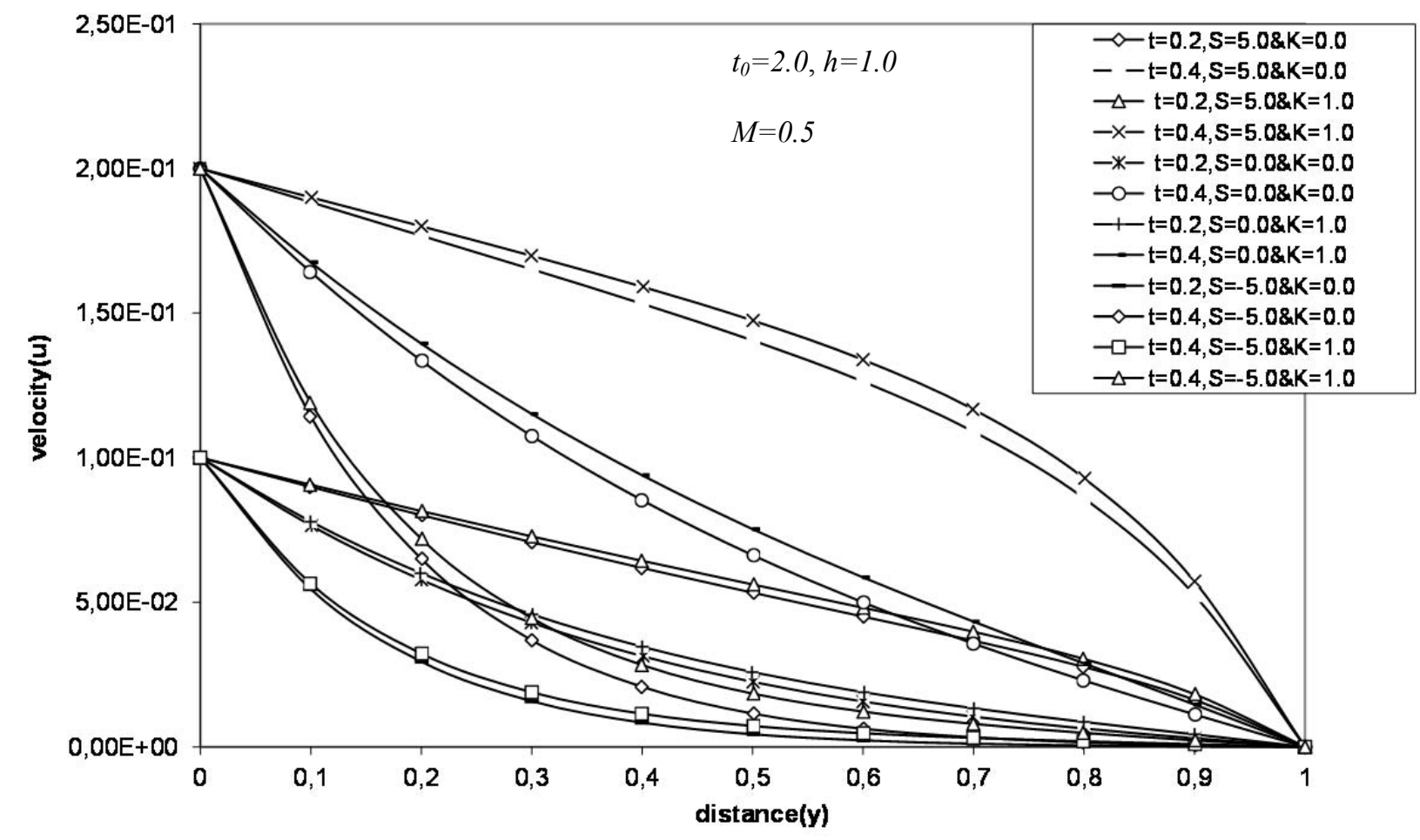

Fig.5. Variation of velocity for different $S$ and $t$.

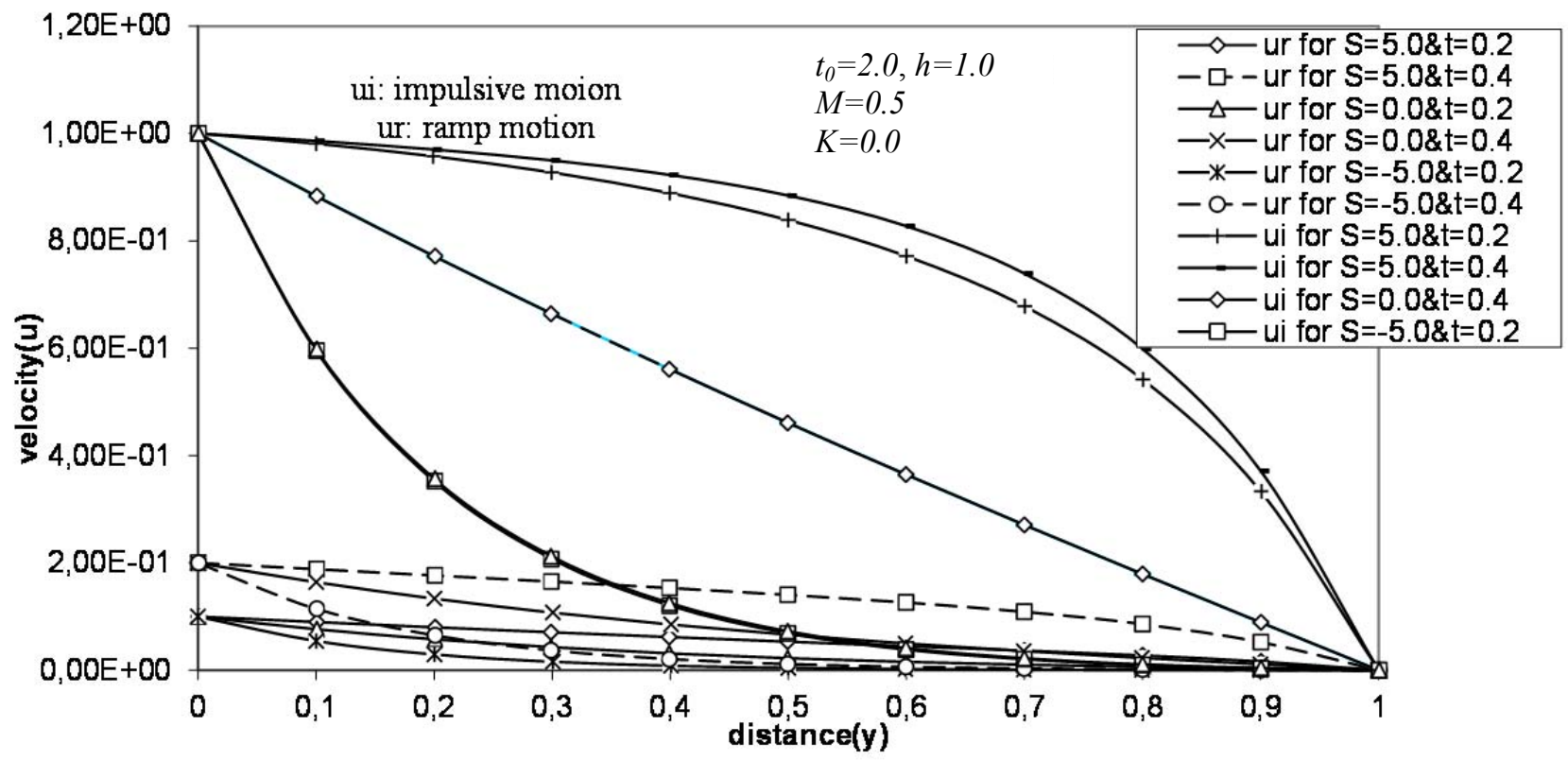

Fig.6. Variation of velocity for different $S$ and $t$. 


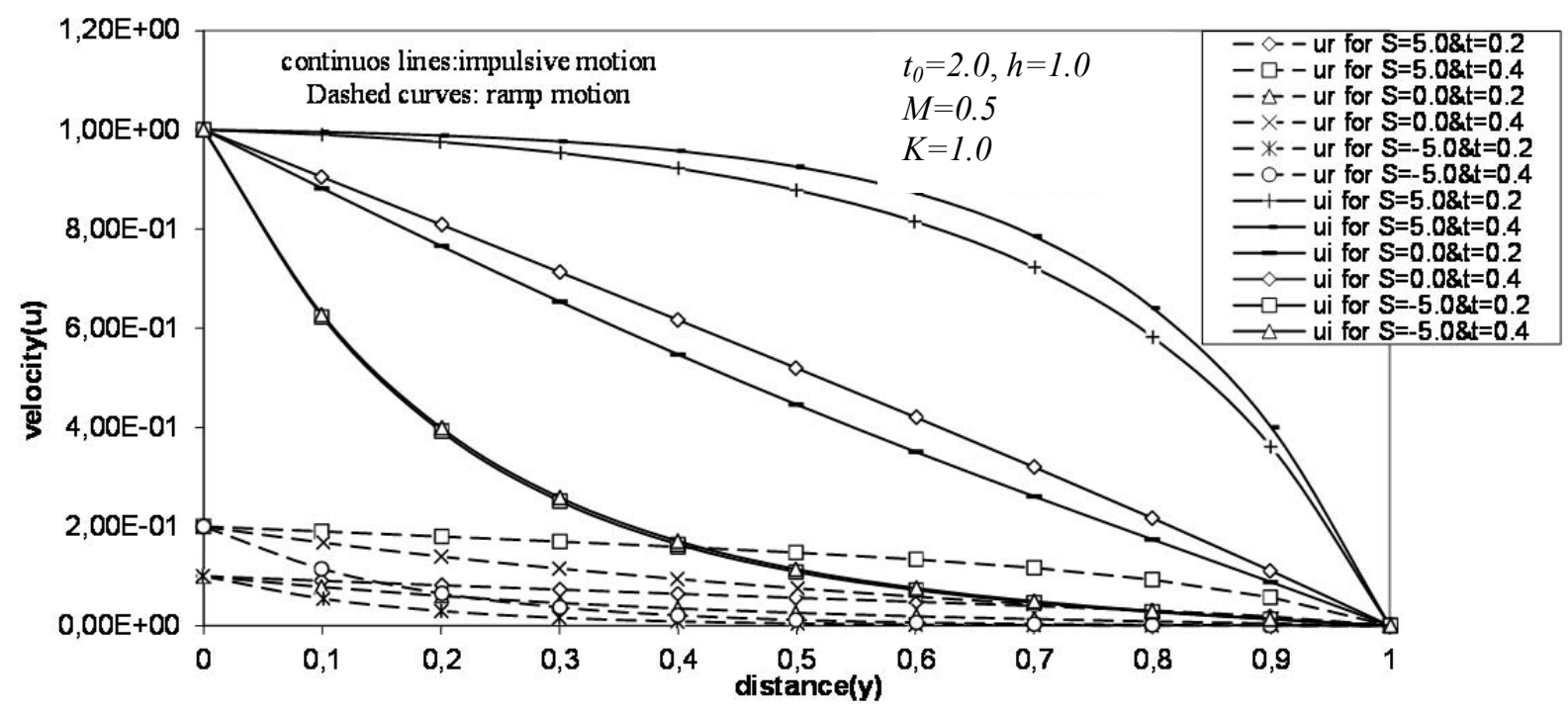

Fig.7. Variation of velocity for different $S$ and $t$.

The variation of the skin friction at the lower and upper porous plate for different values of the injection/suction parameter for a fixed value of the magnetic field $\mathrm{M}$, when $K=0.0$ and $K=1.0$ is shown in Figs 8 and 9 , respectively.

Figure 8 shows that at the lower porous plate, in the presence of suction, the skin friction decreases with an increase in time for a certain range of time $\left(t=t_{0}\right)$ and attains its minimum value. The skin friction increases with an increase in time and reaches its steady state value. This figure also reveals that the skin friction at the lower moving porous plate is higher for a certain range of time when the magnetic lines of force are fixed relative to the moving porous plate than when fixed relative to the fluid. The steady state skin friction is however higher when the magnetic lines of force are fixed relative to the fluid than when fixed relative to the moving porous plate. It is interesting to note that the skin friction in the presence of mass injection remains constant with time.

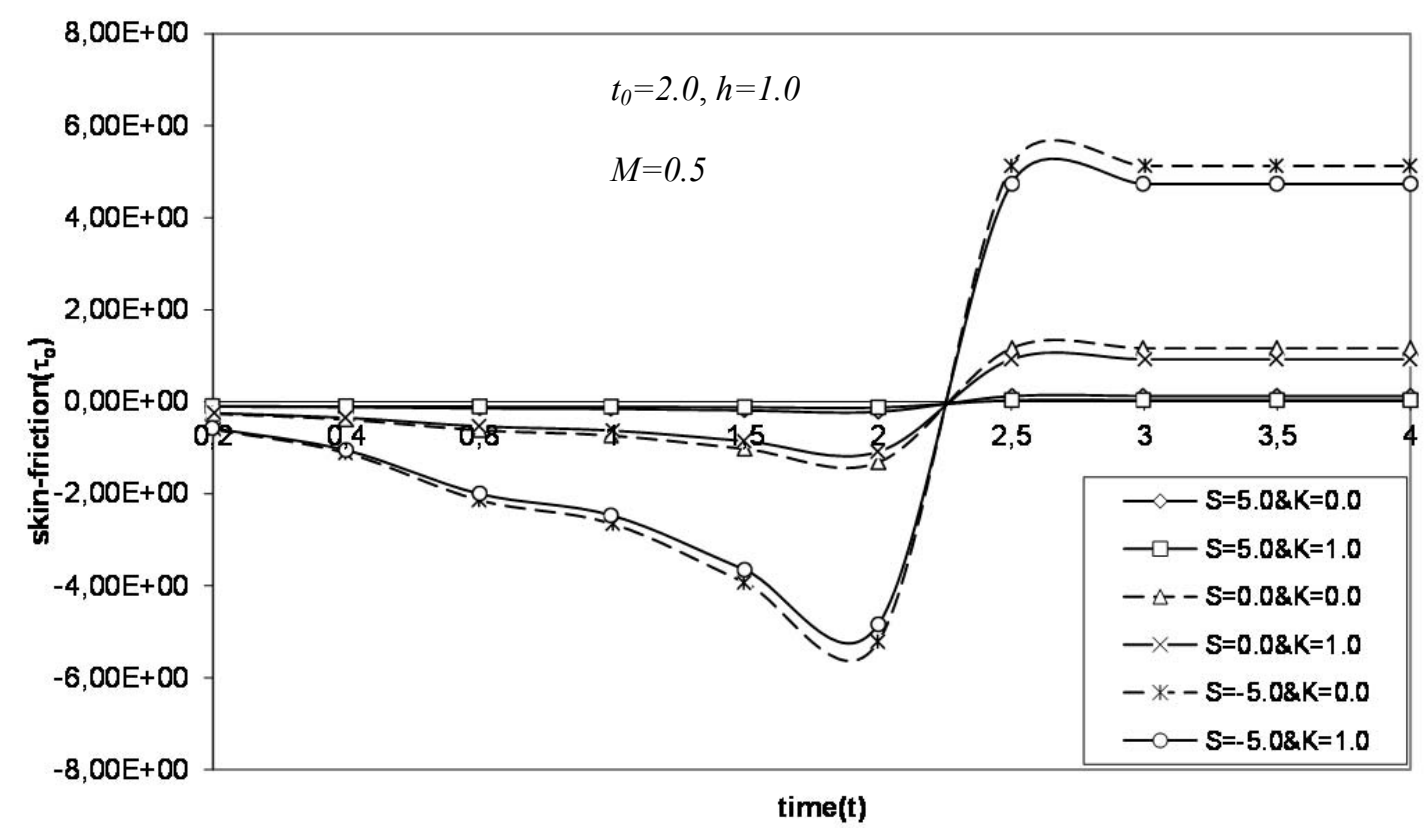

Fig.8. Variation of skin-friction for different $S$ and $t$ at $y=0$. 
Figure 9 reveals that, in the presence of injection at the lower porous plate, the skin friction at the upper porous plate decreases with an increase in time for a certain range of time $\left(t=t_{0}\right)$ and attains its minimum value. The skin friction increases with an increase in time and reaches its steady state value. This figure also reveals that under injection lower porous plate, the skin friction at the upper plate is higher for a certain range of time when the magnetic lines of force are fixed relative to the fluid than when fixed relative to the moving porous plate.

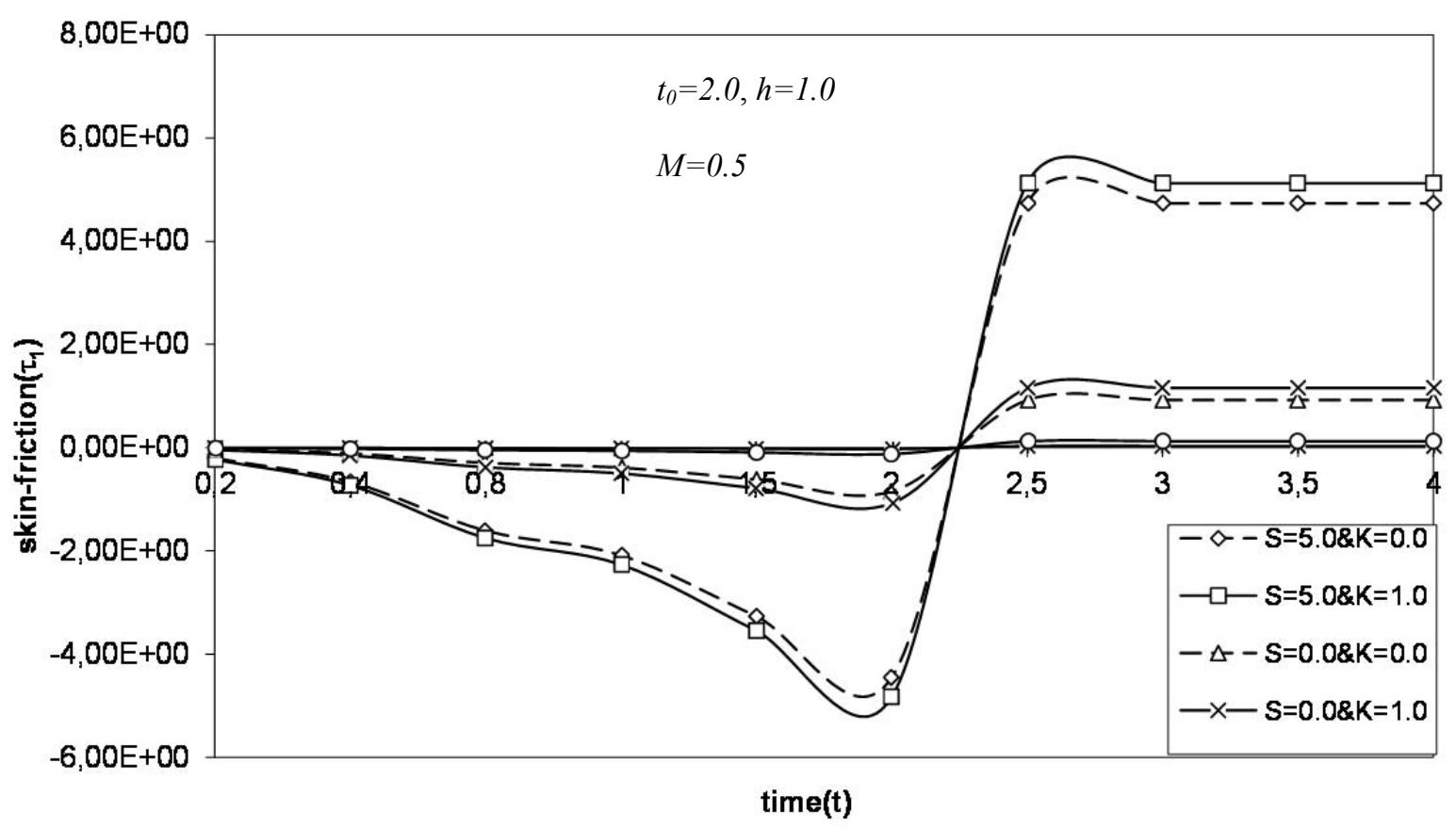

Fig.9. Variation of skin-friction for different $S$ and $K$ at $y=1$.

The steady state skin friction is however higher when the magnetic lines of force are fixed relative to the moving porous plate than when fixed relative to the fluid. It is interesting to note that the skin friction in the presence of suction remains constant with respect to time.

Figures 10 and 11 give a comparative view of the skin friction at the lower moving and upper porous plate, for different values of $S$, when the plate is in ramp or impulsive motion, when $K=0.0$ or $K=1.0$ respectively.

Figure 9 reveals that under mass suction the skin friction due to ramp motion of the lower boundary decreases with an increase in time and attains its minimum value and then increases and reaches its steady state value, whether $K=0.0$ or $K=1.0$. Also, it is clear that the skin friction due to ramp motion of the porous plates coincides with impulsive motion at large values of time. Hence, we concluded that in the case of a steady state the skin friction is almost same whether the plate is in impulsive or ramp motion.

Figure 10 shows the variation of the skin friction versus time at the upper porous plate, for different values of $S$, when the plate is in ramp or impulsive motion when $K=0.0$ or $K=1.0$. It is observed that in the presence of mass injection the skin friction decreases with an increase in time and attains its minimum value and then increases and reaches its steady state value when $K=0.0$ or $K=1.0$. It is also clear that the skin friction due to ramp motion as well as impulsive motion of the boundary coincides at large values of time. 


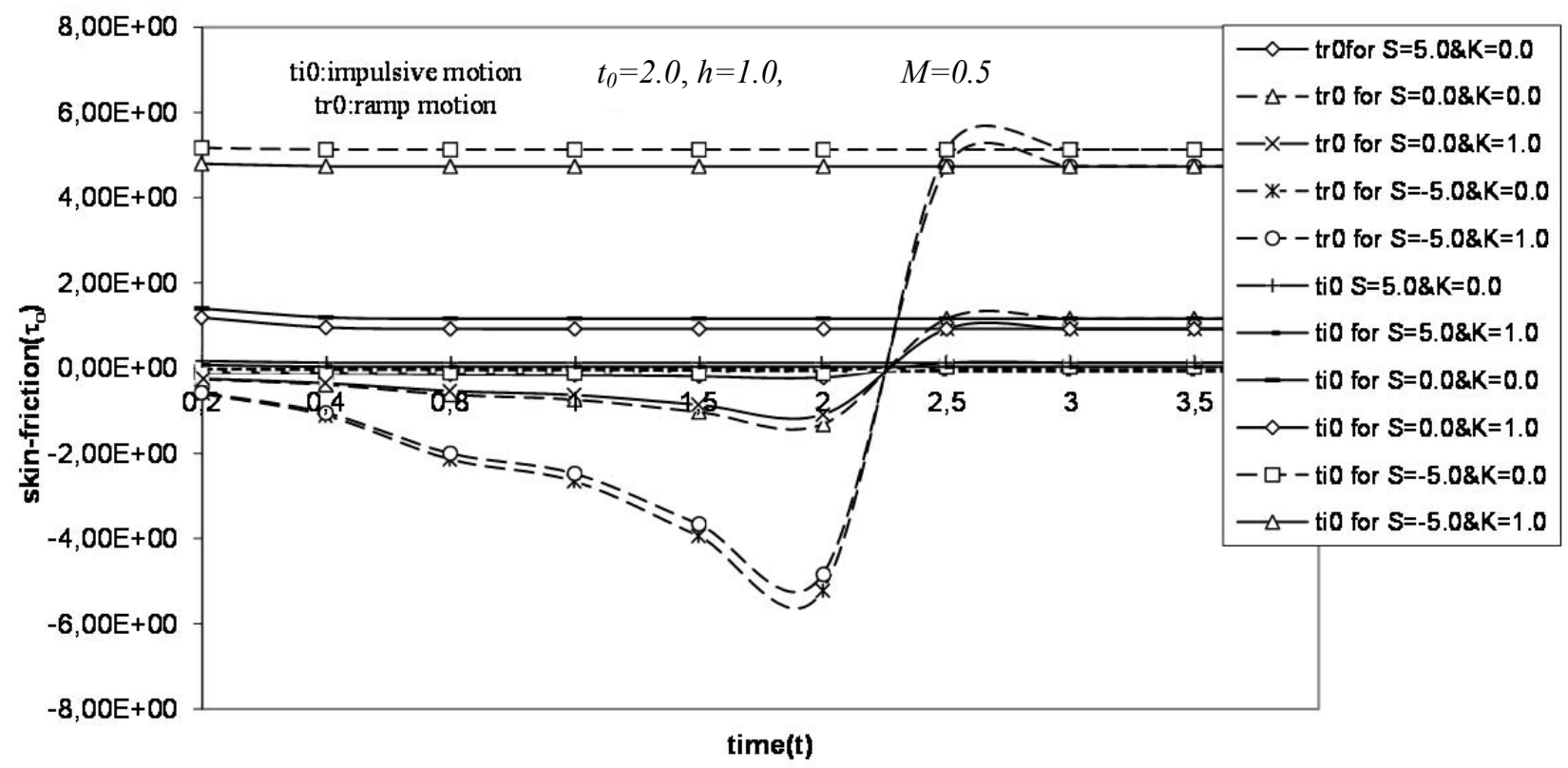

Fig.10. Variation of skin-friction for different $S$ and $K$ at $y=0$.

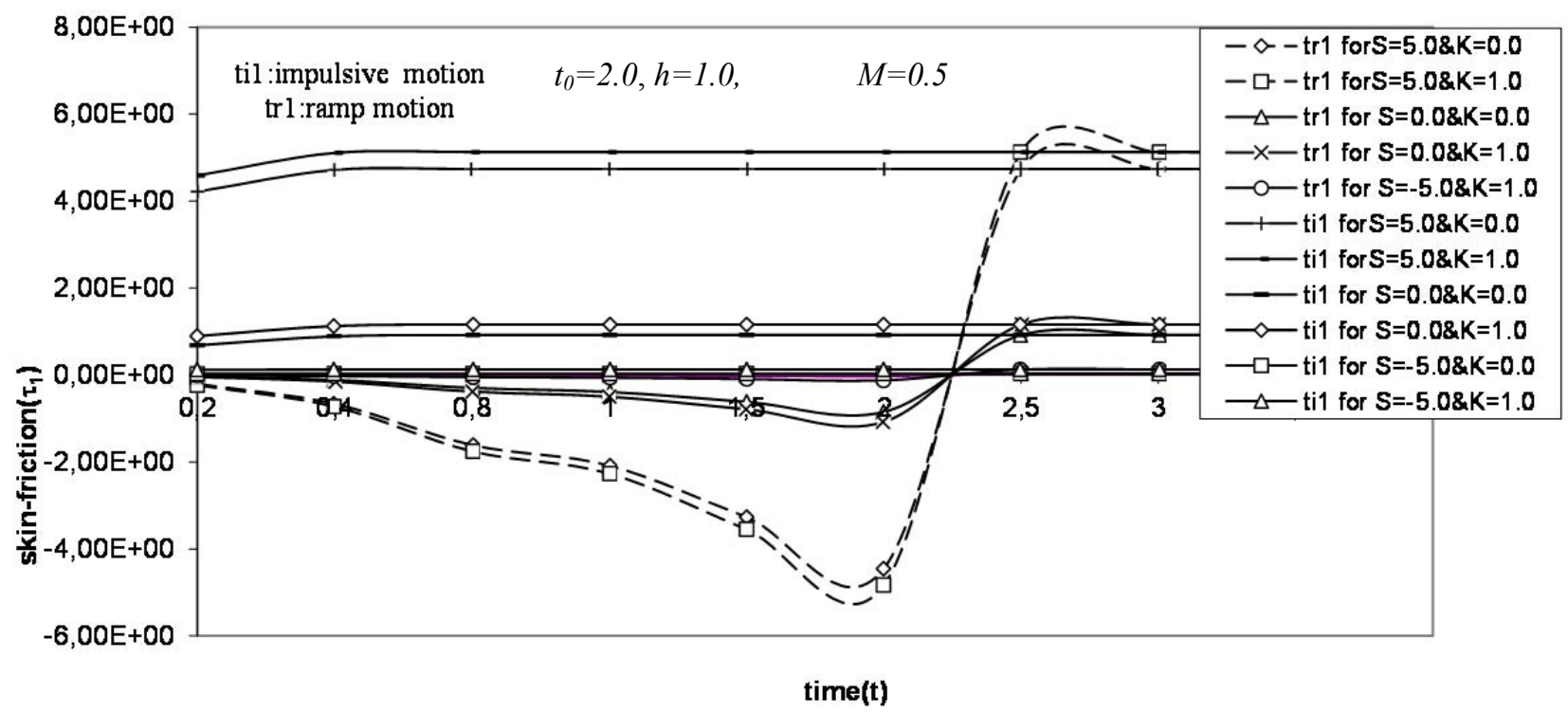

Fig.11. Variation of skin-friction for different $S$ and $K$ at $y=1$.

\section{Summary and conclusion}

The effects of viscosity, magnetic field and mass leakage on the unsteady MHD Couette flow of an incompressible, viscous and electrically conducting fluid have been analyzed when the flow is generated due to ramped motion of the porous plate. A unified closed form analytical solution has been obtained for fluid velocity and skin-friction corresponding to the cases of a magnetic field fixed relative to the fluid or moving porous plate. The variations of velocity and skin-friction have been discussed for different values of the Hartmann number and suction/injection parameter. The flow formation due to ramped motion of one of the porous plates has also been compared with the flow formation due to constant motion of one of the porous 
plates. It has been observed that the effect of injection increases the velocity while suction decreases it. It is seen from the figures that the velocity increases in the presence of the injection parameter and decreases with suction at the moving porous plate, whether the magnetic lines of force are fixed with respect to the fluid or the moving porous plate. It also shows that velocity is higher when the magnetic lines of force are fixed relative to the moving porous plate than when fixed relative to the fluid in the presence of suction or injection. Furthermore, the results indicate that the effect of injection increases the velocity while suction decreases it.

\section{Acknowledgement}

The authors wish to acknowledge the financial and moral support of the Authorities of Ahmadu Bello University, Zaria, Nigeria to in this research project.

\section{Nomenclature}

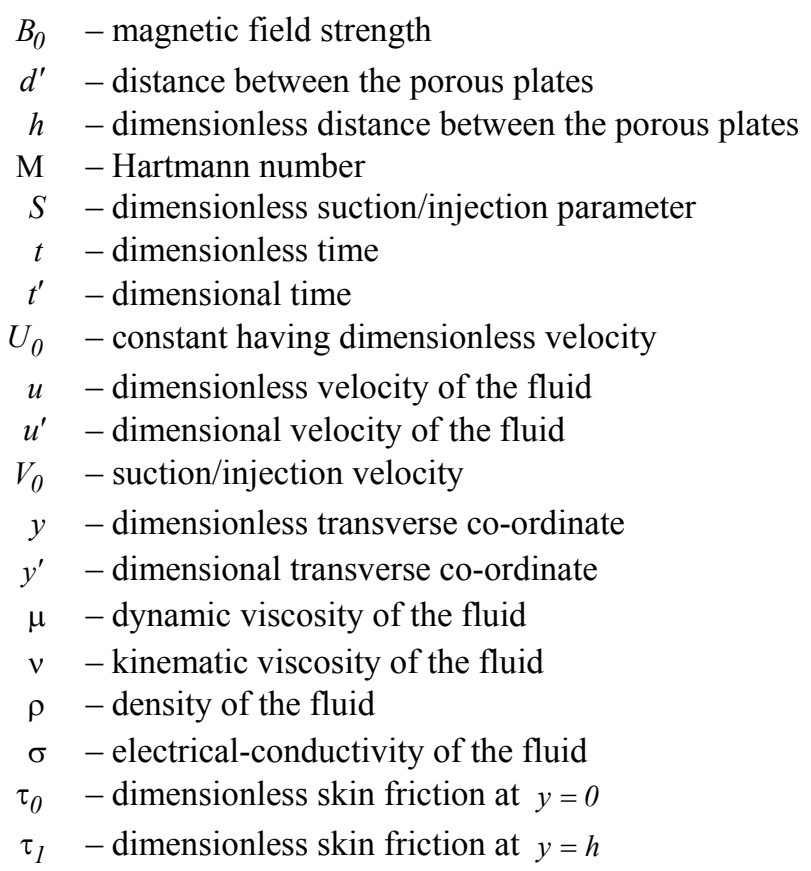

\section{References}

Abramowitz B.M. and Stegun I.A. (1965): Handbook of Mathematical Functions. - New York: Dover.

Carslaw H.S. and Jaeger J.C. (1963): Operational Methods in Applied Mathematics (2 ${ }^{\text {nd }}$ Edition). - New York: Dover.

Chandran P., Sacheti N.C. and Singh A.K. (1993): Effects of rotation on unsteady hydromagnetic Couette flow. Astrophysics and Space Science, vol.20, Issue 29, pp.1-10.

Guria M., Jana R.N. and Ghosh S.K. (2006): Unsteady Couette flow in a rotating system. - Int. Jr. of Non-Linear Mechanics, vol.41, pp.838-843.

Hartmann L. (1937): Hg-dynamics 1. Theory of laminar flow of an electrically conductive liquid in a homogeneous magnetic field. Kg.1. Danske videnskabernes selskab. - Math. Fys. Medd., vol.15.

Hassanien A. and Mansour M.A. (1990): Unsteady magneto hydrodynamic flow through a porous medium between two parallel plates. - Astrophysics and Space Sciences, vol.163, pp.241-246. 
Jha B.K. and Apere C.A. (2010): Combined effect of Hall and ion slip currents on unsteady MHD Couette flows in a rotating system. - Phys. Soc. Jpn, vol.79, pp.104401-9.

Jha B.K. and Jibril H.M. (2012): Effects of transpiration on the MHD flow near a porous plate having ramped motion.Journal of the Physical Society of Japan, vol.81, pp.024401-6.

Katagiri M. (1962): Flow formation in Couette motion in magneto-hydrodynamics. - Jr. of Physical Soc. of Japan, vol.17,11, p.393.

Longwell P.A. (1966): Mechanics of Fluid Flow. - New York: McGraw-Hill Company, p.158.

Panton R.L. (1996): Incompressible Flow (second edition). - New York: J. Wiley, p.310.

Schlichting H. and Gerstein K. (2000): Boundary Layer Theory. $-8^{\text {th }}$ revised and enlarged edition (English). New York: Springer- Verlag.

Shalybkov D.A. (2006): Hydrodynamic and hydromagnetic stability of the Couette flow. - Physiks - Uspekhi, vol.52, 9 , pp.915-935.

Singh A.K. and Kumar N. (1983): Unsteady magneto-hydrodynamics Couette flow. - Wear, vol.89, p.125.

Singh A.K., Sacheti N.C. and Chandran P. (1994): Transient effects on magneto hydrodynamic Couette flow with rotation accelerated motion. - Int. Jr. Eng. Sciences, vol.32, pp.133-139.

White F.M. (1991): Viscous Fluid Flow (second edition). - New York: McGraw-Hill Company.

Received: September 18, 2012

Revised: July 16, 2013 